\title{
SELECTION OF V-BELT FOR POWER TRANSMISSION IN AGRICULTURAL MACHINERY
}

\author{
M. M. Billah, M. S. Hossain', M. R. Islam² and M. A. Rahman' \\ Department of Computer Science \& Mathematics, Bangladesh Agricultural University \\ Mymensingh-2202, Bangladesh
}

\begin{abstract}
The solution of a v-belt design problem depends upon many data tables, figures, equations and sequence of calculations. To solve such a problem a computer program is developed which facilitates the design procedure by fast computation with less drudgery and more accuracy. Computed result shows the diameter of smaller and larger sheave, center distance, belt length, belt number, required number of belt, belt cross-section, as output after calculation. The computer-generated output by using this program is found more accurate and efficient than the conventional calculation method.
\end{abstract}

Key words : V-belt selection, Computer program, Agricultural machinery

\section{INTRODUCTION}

With the advancement of agricultural mechanization the use of agricultural machinery is widely increased. For the power transmission from the power source to the machinery V-belt is mostly used in many agricultural machinery such as power tiller, tractor, combine harvester, reaper, seeding machines, thresher, pump, winnowing machines, huller mills etc. V-belt has diversified use due to its distinct advantages that, it absorb vibration and shock, tending to transmit only a minimum to the connected shaft, it is quiet, if properly maintained it can be designed to have a long trouble - free life.

A design problem may have many correct answers and in some cases no acceptable answer. The solution of a design problem depends upon many factors: some definite in value and quite variable, some depends on restrictions that leave the designers with no choice. The solution of a design contains the thought, judgments and integrity of the designer. It is the designer's creation (Doughtie et al., 1964).

A computer program is a tool that consists of thousands of instructions and executes them in correct sequence, make decisions and check its own work. Most mechanical design problems do not have a unique solution and require the trial-and-error method of solution. Such problems can be solved by computer programming, which will yield all the possible solutions. Among those solutions, it is much easier to select the best design.

\footnotetext{
1 Department of Farm Power and Machinery, Bangladesh Agricultural University,

2 Department of CSE, Manarat Intl. University, Dhaka, Bangladesh
} 
In science and engineering, application of computer system is virtually unlimited. Its extensive use will continue strongly not only to reduce manual drudgery and time saved, but also the horizons of learning are being extended (Black and Adams, 1968).

Selection of V-belt needs trial-and-error method of solution using several data tables and equations which is time consuming and laborious manual calculation. Therefore to reduce drudgery, time and for accuracy a computer program is developed to select V-belt with precision and accurate calculation.

\section{METHODOLOGY}

\section{Design consideration}

In design of this computer program, the first priority was to provide an easily understandable hassle free user interface. As most computers are running on windows operating system (OS), for better compatibility visual basic programming language was chosen. To store several data table an MS Access Database file was used as the backhand database in this program. The main program connects with this access database through Microsoft Jet 4.0 DB provider. As the compiler and all the components of this program are from same vendor, it works very smoothly on any window based PC.

\section{General procedure for v-belt selection}

The steps stated below have been followed in the development of the computer program. All tables, equations and data are used from book titled "Design of Machine Elements" by V. M. Faires (1965).

\section{Determination of service factor ( $N s f$ )}

Service factor $\left(N_{s f}\right)$ has been determined from the table coded in the program for machine type (driven machine and driving machine).

In this program driven machine and driving machine are two inputs and are selected from two different combo box lists, and mathematical equation were used for operational conditions

\section{Determination of design horsepower}

Design horsepower has been calculated by the equation -

Design hp $=N_{s f} \times$ transmitted hp

The case where transmitted hp or consumed hp was not mentioned the nameplate horsepower on the motor or engine is used.

\section{Determination of belt section}

The belt section has been determined from the Fig. 1 using the value of design hp and rpm of smaller sheave. RPM of smaller sheave is an input and the figure was 
incorporated by using the rules of geometry. Point on a particular cross-section is selected by satisfying the geometric conditions of this point.

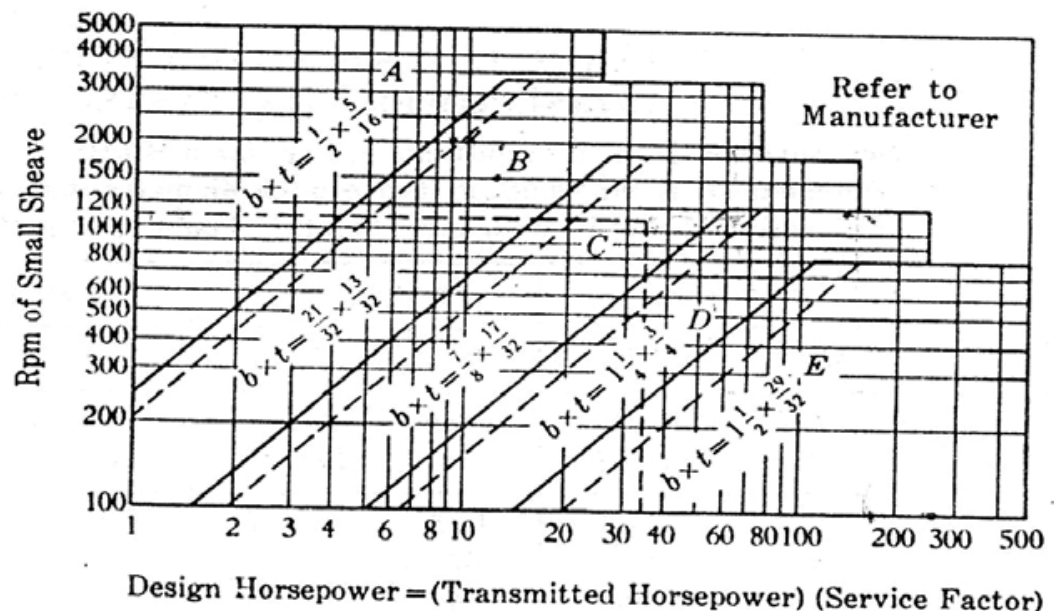

Fig. 1. Belt section from horsepower and speed

\section{Determination of belt speed (Vm)}

Belt speed of V-belt determined by the following equation

$\mathrm{V}_{\mathrm{m}}=\left(\pi \times \mathrm{D}_{1} \times \mathrm{n}_{1}\right) / 12$

where,

$\mathrm{V}_{\mathrm{m}}=$ belt speed, $\mathrm{fpm}$

$\mathrm{D}_{1}=$ diameter of smaller sheave such as $3,5.4,9$ and 13 inch for the belt section $\mathrm{A}, \mathrm{B}, \mathrm{C}$ and $\mathrm{D}$ respectively as minimum smaller sheave diameter if not specified.

$\mathrm{n}_{1}=\mathrm{rpm}$ of smaller sheave

\section{Determination of larger sheave diameter (D2)}

$\mathrm{D}_{2}$ has been determined by the following equation

$\mathrm{D}_{2}=\frac{\mathrm{n}_{1} \mathrm{D}_{1}}{\mathrm{n}_{2}}$

where,

$\mathrm{n}_{1}=\mathrm{rpm}$ of smaller sheave

$\mathrm{n}_{2}=\mathrm{rpm}$ of larger sheave

$\mathrm{D}_{1}=$ diameter of smaller sheave.

\section{Determination of smaller sheave diameter factor $(K d)$}

$K_{d}$ has been selected for the value of $\left(\mathrm{D}_{2} / \mathrm{D}_{1}\right)$ from the table coded in this program. 


\section{Determination of rated horsepower}

Rated horsepower has been determined by using the equation,

Rated hp $=\left[\mathrm{a}\left(10^{3} / \mathrm{v}_{\mathrm{m}}\right)^{0.09}-\left\{\mathrm{c} /\left(\mathrm{K}_{\mathrm{d}} \times \mathrm{D}_{1}\right)\right\}-\left\{\mathrm{e}\left(\mathrm{v}_{\mathrm{m}}{ }^{2} / 10^{6}\right)\right\}\right]\left(\mathrm{v}_{\mathrm{m}} / 10^{3}\right) \ldots \ldots \ldots$

where,

$K_{d}=$ Smaller sheave diameteral factor and a, c, e, are the rated hp constants selected from the table stored in the internal database of this program.

\section{Determination of designed belt length, center distance, belt number}

For selected belt section belt length, center distance, belt number have been determined by using the following equations-

$$
\begin{aligned}
& \mathrm{B}=4 \mathrm{~L}-6.28\left(\mathrm{D}_{2}+\mathrm{D}_{1}\right) \ldots \ldots \ldots \ldots \\
& \mathrm{C}=\left[\mathrm{B}+\sqrt{\mathrm{B}^{2}-32\left(\mathrm{D}_{2}-\mathrm{D}_{1}\right)^{2}}\right] / 16
\end{aligned}
$$

Here, equation- 5 is solved by selecting the values of ' $\mathrm{L}^{\prime}$ (belt length) from the table stored in the internal database of this program. The value of ' $C$ ' of equation- 6 is checked with the given value of center distance and selected the value nearest to the given value of ' $C$ '. The designed belt length and its corresponding belt number were selected from table stored for the selected value of ' $C$ '

\section{Determination of correction factor $(K \theta)$ for an arc of contact}

$K_{\theta}$ has been determined from the table stored in the internal database of this program for the value of $\left(D_{2}-D_{1}\right) / C$ and type of belt drive.

\section{Determination of KL as the correction factor for length}

$K_{L}$ has been determined by using the selected length and belt section from the table stored in the internal database of this program.

\section{Determination of adjusted rated horsepower}

The horsepower from rating equation must be adjusted for length of belt and arc of contact.

Adjusted rated $h p=($ rated $h p) K_{\theta} K_{L}$

\section{Determination of number of belt needed}

Number of belt needed determined by using the equation.

Number of belt needed $=$ Design $h p /$ Adjusted rated hp

\section{Flow chart}

Following flow chart is used for the program with the objective of selecting V-belt. 


\section{Flow chart}
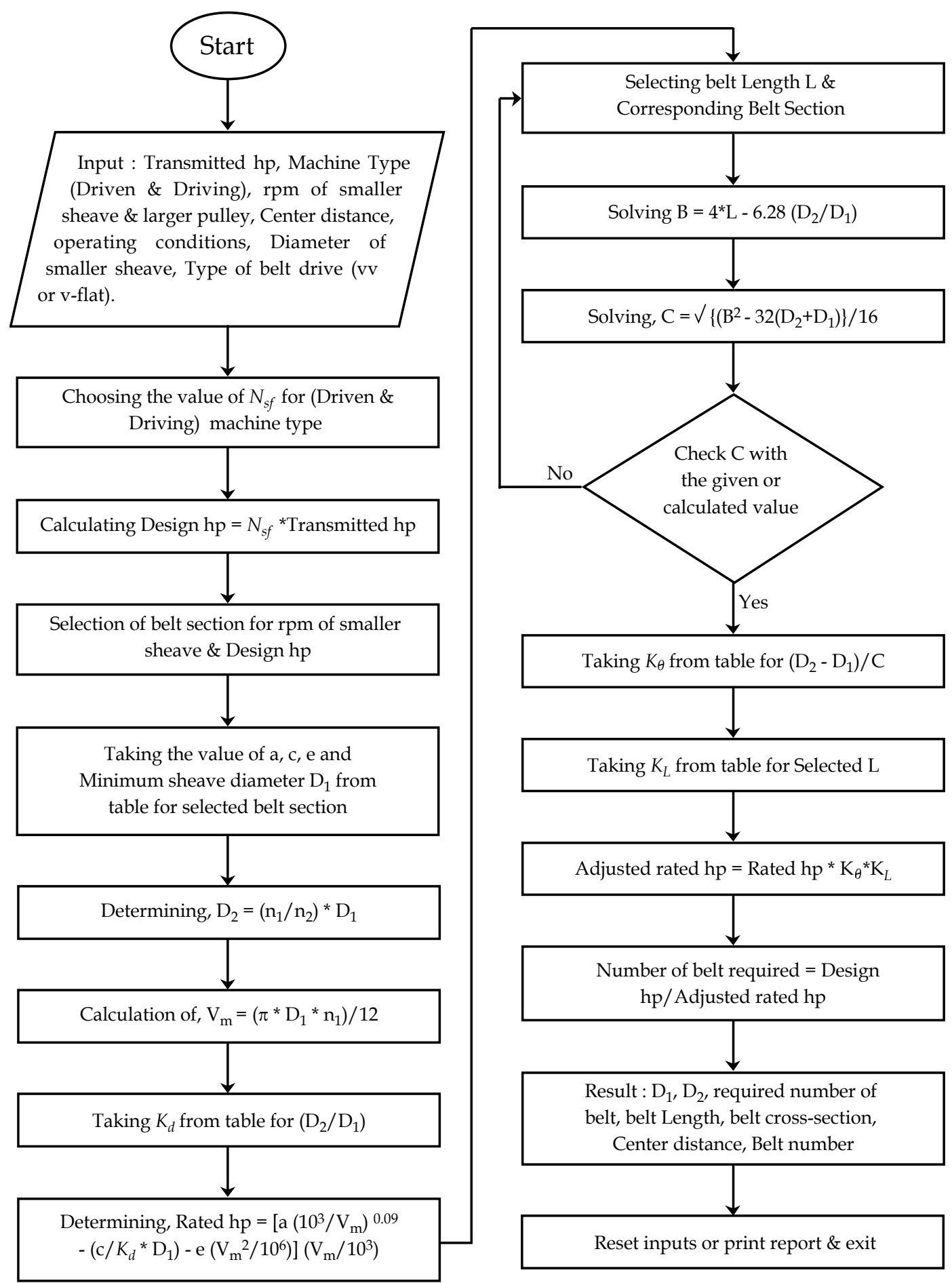


\section{RESULTS AND DISCUSSION}

Computer program written in visual basic is developed to select the V-belt. In the program all tables and figures are incorporated to read the value of the constants such as $N_{s f}, K_{d}, K_{\theta}$, and $K_{L}$.

As an example, a problem is solved from the book "Problem on The Design of Machine Elements" by V. M. Faires (1965). The problem is, "A 200-hp, 600-rpm, induction motor is to drive a jaw crusher at 125-rpm; starting load is heavy; operating with shock; intermittent service; $C=113$ to 123 in. Recommend a multiple V-flat drive for this application."

The solution is shown in Fig. 2. The selected belt section, belt No., diameter of smaller sheave, diameter of larger sheave, center distance, belt length and required number of belt are D, 360, 13 in., 62.4 in., 118.64 in., 360.8 in. and 20 respectively. Total number of the belt is too high because of the smallest recommended diameter of smaller sheave taken from table. Keeping all data same and only increasing the diameter of smaller sheave say 20 inch., the required belt number is reduced to 10 (shown in Fig. 3). Only by increasing the diameter of the smaller sheave by $50 \%$, number of belt becomes half. Lower smaller sheave diameter needs more number of belts because of more stress on the belt. With the increase in smaller sheave diameter, although total required number of belt decreased but the belt length and larger sheave diameter increased.

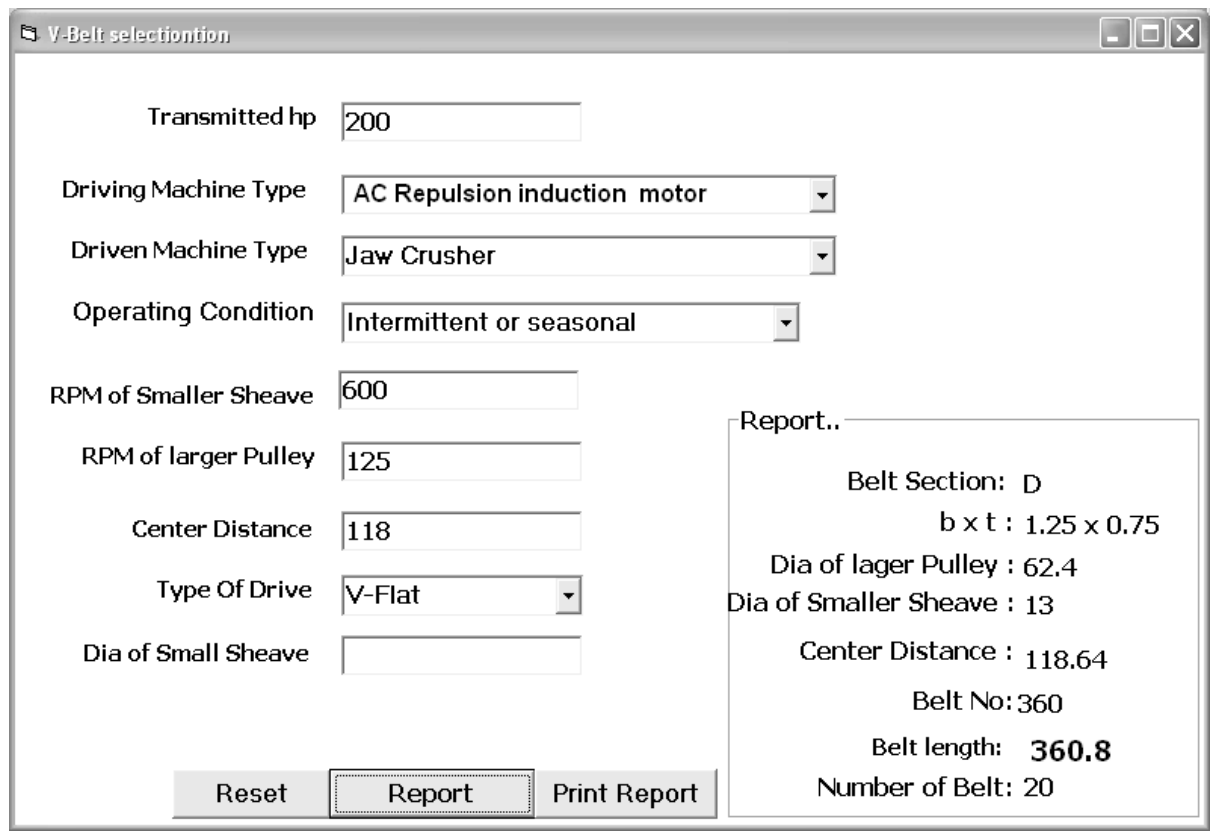

Fig. 2. Main interface for selecting the V-belt (results with the recommended least diameter of the smaller sheave) 


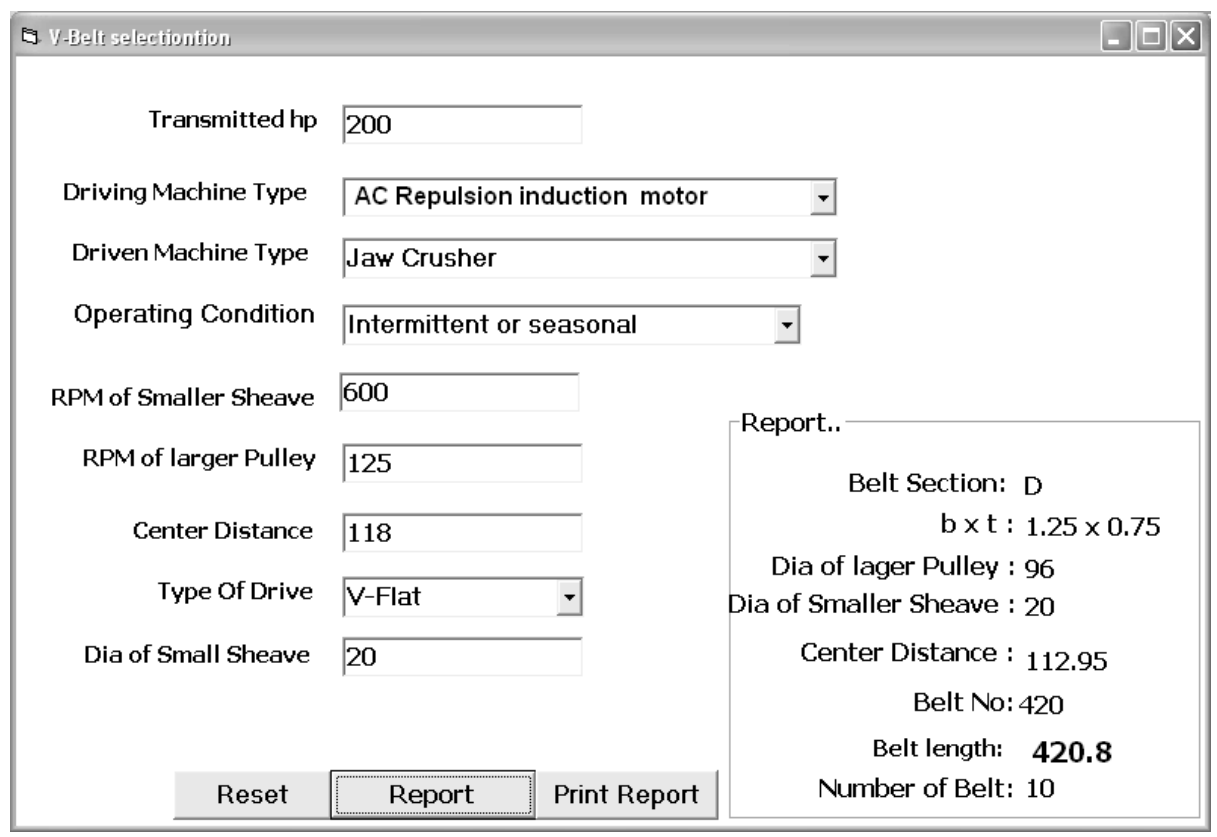

Fig. 3. Main interface for selecting the V-belt (results with the increased diameter of the smaller sheave)

For the selection of center distance whenever a range is given the mid value is to be used as input and the program selects the nearest center distance to the given value.

If the value of diameter of smaller sheave is used as input the program shows the result according to the input value. Otherwise the computer program takes the value of minimum smaller sheave diameter as 3, 5.4, 9 and 13 inch for the belt section A, B, C and D respectively.

\section{CONCLUSION}

From the above discussion it is clearly evident that this computer program for selecting V-belt is a very efficient tool in comparison with the conventional pen-paper calculation procedures. If conventional technique is used for selecting V-belt, it is laborious and time consuming. In such cases this computer program can be used for selecting V-belt easily. Giving values of transmitted hp, machine type (driven \& driving), rpm of smaller sheave \& larger pulley, center distance, operating conditions, diameter of smaller sheave and the type of drive (vv or v-flat) etc, as input finally this computer program shows the values of the diameter of smaller and larger sheave, center distance, belt length, belt number, required number of belt, belt cross-section, as output result. The computer generated output by using computer program has been found more accurate and efficient than the conventional calculation results. 
This program will effectively assist the design engineers and agriculturists working in the field to select the V-belt accurately and precisely.

\section{REFFEENCES}

Black, P. H. and Adams, O. E. 1968. Machine Design. 3rd edn. McGraw-hill Company. New York.

Doughtie, V. L., Vallanc, A. and Kreisle, L. F. 1964. Design of machine members. $4^{\text {th }}$ edn. Mc-Graw Hill Company, New York.

Faires, V. M. 1965. Design of Machine Elements. $4^{\text {th }}$ edn. The MacMillan Company. New York. 